\title{
Concept for an Accurate Calibration of Long Baseline Two-Way Satellite Time and Frequency Transfer (TWSTFT) Links via Two Separated Transponders on one Telecommunication Satellite
}

\author{
D. Piester, T. Feldmann, A. Bauch \\ Physikalisch-Technische Bundesanstalt (PTB) \\ Braunschweig, Germany \\ dirk.piester@ptb.de
}

\author{
M. Fujieda, T. Gotoh \\ National Institute of Information and Communications \\ Technology (NICT) \\ Tokyo, Japan
}

\begin{abstract}
Two-way satellite time and frequency transfer (TWSTFT) is the technique which allows time scale comparisons at the nanosecond level. Until now, this uncertainty level is restricted to those institutes which both can exchange signals through the same single transponder of one telecommunication satellite. Only in this case the calibration scheme of circulating a portable TWSTFT reference station is applicable. This condition is not fulfilled in the operational intercontinental links, e.g. between Asia and Europe. Calibration of the TWSTFT link is in such cases achieved by adjusting the TWSTFT results to those obtained with a calibrated GPS link. The uncertainty is then limited by the uncertainty of the GPS link, which is commonly estimated to be at the level $u_{B}=5 \mathrm{~ns}$. We propose an experimental configuration which allows determination of all important delay differences in a long baseline link including the differential delays between the operational ground stations as well as the differential transponder delay between the two separated transponders used on the satellite. The latter has never been determined on a flying satellite. We propose to exchange two portable TWSTFT stations and two GPS receivers between the two ground stations to be calibrated. We estimate the overall uncertainty for the calibration to be at a level of $2 \mathrm{~ns}$. We also discuss briefly the ability of calibrating a TWSTFT link as a whole by means of GPS on the same level of uncertatinty.
\end{abstract}

\section{INTRODUCTION}

Two-way satellite time and frequency transfer (TWSTFT) is the technique which allows time scale comparisons at the nanosecond level [1]. Until now, this uncertainty level is restricted to those institutes which both can exchange signals through a single transponder of one telecommunication satellite (see Fig. 1 for illustration). Only in this case the calibration scheme of circulating a portable TWSTFT reference station is applicable. This condition is not fulfilled in the operational intercontinental links e.g. between Asia and Europe (see Fig. 2). Here the signal is converted in two transponders one for each propagation direction. Calibration of the TWSTFT link is in such cases achieved by adjusting the TWSTFT results to those obtained with a calibrated GPS link. The uncertainty is then limited by the uncertainty of the GPS link, which is commonly estimated to be at the level of $u_{\mathrm{B}}=5 \mathrm{~ns}[2]$.

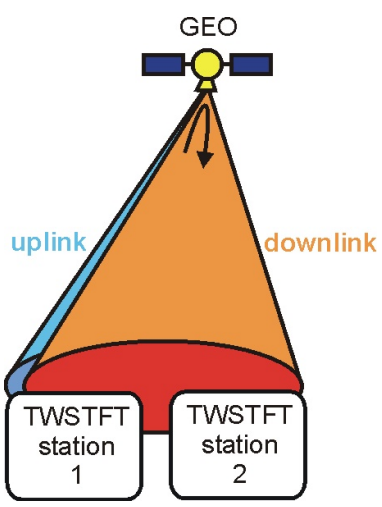

Figure 1. The single transponder configuration which allows a calibration of TWSTFT links by a portable reference TWSTFT station. Examples for such links are the ones between the European laboratories, the Intra-Asia connections and the link between the USNO and PTB with RF-frequencies in the X-band.

In this paper we propose an experimental configuration which allows the determination of all important delay differences in a long baseline link including the differential delays between the operational ground stations as well as the differential transponder delay between the two separated transponders used. Our proposed configuration includes two portable TWSTFT stations and two GPS receivers which are exchanged between two ground stations to be calibrated. Such a campaign would last not longer than four weeks. We then make use of the fact that the delay changes of GPS time 
transfer equipment is actually significantly smaller during such a short period compared with the above mentioned 5-nsestimate (see Esteban et al. [3]). This 5-ns-uncertainty is based on long term delay variations, which have been observed in the past.

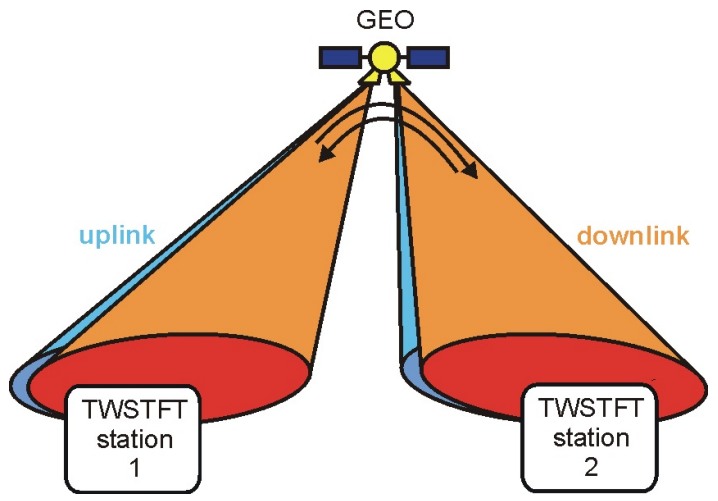

Figure 2. The separated transponder configuration which does not allow the calibration by one portable station. Examples are the links between USA and European labs via IS-4 and the links between Asia and Europe.

This paper is organized as follows: First we develop from the well known "TWSTFT-equations" (see e.g. [4]), a basic set of equations describing the different measurements which have to be performed to derive the delays of all involved components. In the applied relative calibration mode we determine delay differences between operational components and reference equipment or between corresponding components in both signal ways. Thereafter we estimate the uncertainty of the measurements, based on literature values and own experimental results. We discuss the potential applications for this calibration scheme and motivate future investigations.

\section{BASIC EQUATIONS}

In this section the basic equations will be developed for the purpose to compare two physical realizations of UTC at remote sites by a calibrated TWSTFT link via two separated transponders on one telecommunication satellite. We use, if suitable, the nomenclature of existing literature [1], [4] and we deviate only if necessary. The operational link consists of two TWSTFT ground stations 1 and 2, which are located at the two remote sites 1 and 2, respectively. For the calibration we make use of two portable TWSTFT stations called A and $\mathrm{B}$ and two (also portable) GPS receivers C and D. An index indicates the site where the portable equipment is located during the measurements. In Fig. 3 a scheme of the used equipment is depicted.

To develop the necessary equations we start with the time interval counter readings TW $(i)$ obtained at stations 1 and 2:

$$
\begin{aligned}
\mathrm{TW}(1)= & \mathrm{UTC}(1)-\mathrm{UTC}(2) \\
& +\mathrm{TX}(2)+\mathrm{SP}(2)+\mathrm{RX}(1)+\mathrm{SCD}(2) \\
\mathrm{TW}(2)= & \mathrm{UTC}(2)-\mathrm{UTC}(1) \\
& +\mathrm{TX}(1)+\mathrm{SP}(1)+\mathrm{RX}(2)+\mathrm{SCD}(1)
\end{aligned}
$$

$\mathrm{UTC}(i)$ is the local realization of $\mathrm{UTC}$ at site $i$. TX $(i)$ and $\mathrm{RX}(i)$ are the signal delays of the transmission and receiving paths of the respective groundstations. SP(i) is the signal path delay from site $i$ to site $j$. If all other delays (i.e. those due to the ionosphere, troposphere, etc.) on the signal path except the transponder delays SPT $(1) \neq \mathrm{SPT}(2)$ are equal to first order we can assume $\mathrm{SPT}(1)-\mathrm{SPT}(2)=\mathrm{SP}(1)-\mathrm{SP}(2) . \mathrm{SCD}(i)$ is the Sagnac correction (see [1] for details). Subtracting (2) from (1) gives:

$$
\begin{aligned}
\mathrm{UTC} & (1)-\mathrm{UTC}(2)=1 / 2[\mathrm{TW}(1)-\mathrm{TW}(2)] \\
& +1 / 2\{[\mathrm{TX}(1)-\mathrm{RX}(1)]-[\mathrm{TX}(2)-\mathrm{RX}(2)]\} \\
& +1 / 2[\mathrm{SP}(2)-\mathrm{SP}(1)]+[\mathrm{SCD}(2)-\mathrm{SCD}(1)]
\end{aligned}
$$

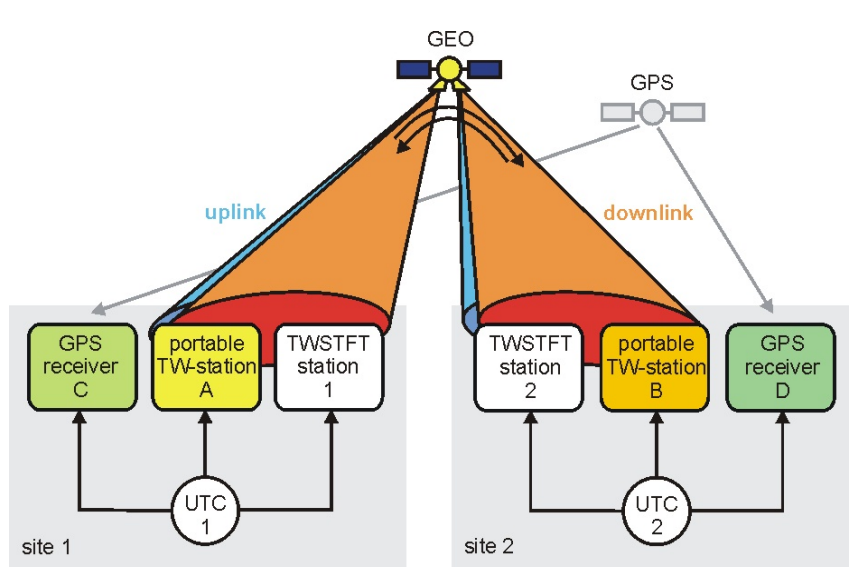

Figure 3. The calibration equipment. The TWSTFT link between two fixed ground stations 1 and 2 at sites 1 and 2, respectively, should be calibrated by employing two portable TWSTFT stations A and B as well as two GPS receivers $\mathrm{C}$ and $\mathrm{D}$.

If we introduce the station dependent delay difference $\operatorname{DLD}(i)=[\mathrm{TX}(i)-\mathrm{RX}(i)]$ we get:

$$
\begin{aligned}
& \mathrm{UTC}(1)-\mathrm{UTC}(2)=1 / 2[\mathrm{TW}(1)-\mathrm{TW}(2)] \\
& +1 / 2[\mathrm{DLD}(1)-\mathrm{DLD}(2)] \\
& +1 / 2[\mathrm{SP}(2)-\mathrm{SP}(1)]+[\operatorname{SCD}(2)-\operatorname{SCD}(1)]
\end{aligned}
$$

This is the basic equation describing the operational link and $[\mathrm{TW}(1)-\mathrm{TW}(2)]$ are the regular measurement quantities. The terms $[\mathrm{DLD}(1)-\mathrm{DLD}(2)]$ and $[\mathrm{SP}(2)-\mathrm{SP}(1)]$ are to be determined in a calibration exercise. The Sagnac correction $[\operatorname{SCD}(2)-\operatorname{SCD}(1)]$ can be calculated with sufficient uncertainty from the positions of the ground stations and the nominal position of the GEO. If we use two portable stations $\mathrm{A}$ and $\mathrm{B}$ instead of the operational ones we get a similar equation:

$$
\begin{aligned}
& \mathrm{UTC}(1)-\mathrm{UTC}(2)=1 / 2\left[\mathrm{TW}\left(\mathrm{A}_{1}\right)-\mathrm{TW}\left(\mathrm{B}_{2}\right)\right] \\
& +1 / 2[\mathrm{DLD}(\mathrm{A})-\mathrm{DLD}(\mathrm{B})] \\
& +1 / 2[\mathrm{SP}(2)-\mathrm{SP}(1)]+[\operatorname{SCD}(2)-\operatorname{SCD}(1)]
\end{aligned}
$$


Also, we operate two (not necessarily calibrated) GPS receivers at both sites to measure the time difference UTC(1) - UTC(2) with an unknown but constant differential offset CD:

$$
\mathrm{UTC}(1)-\operatorname{UTC}(2)=\operatorname{GPS}\left(\mathrm{C}_{1}\right)-\operatorname{GPS}\left(\mathrm{D}_{2}\right)+\mathrm{CD}
$$

Now we exchange the portable TWSTFT stations as well as the GPS receivers as depicted in Fig. 4:

$$
\begin{aligned}
& \mathrm{UTC}(1)-\mathrm{UTC}(2)=1 / 2\left[\mathrm{TW}\left(\mathrm{B}_{1}\right)-\mathrm{TW}\left(\mathrm{A}_{2}\right)\right] \\
& \quad+1 / 2[\mathrm{DLD}(\mathrm{B})-\mathrm{DLD}(\mathrm{A})] \\
& \quad+1 / 2[\mathrm{SP}(2)-\mathrm{SP}(1)]+[\mathrm{SCD}(2)-\mathrm{SCD}(1)]
\end{aligned}
$$

and

$$
\mathrm{UTC}(1)-\mathrm{UTC}(2)=\operatorname{GPS}\left(\mathrm{D}_{1}\right)-\operatorname{GPS}\left(\mathrm{C}_{2}\right)-\mathrm{CD}
$$

Note, that the signs of the double delay difference $[\mathrm{DLD}(\mathrm{A})-\mathrm{DLD}(\mathrm{B})]$ and of the constant offset CD have changed. A combination of the equations (4) to (8) will allow us a distillation of single delays, as discussed in the next section.

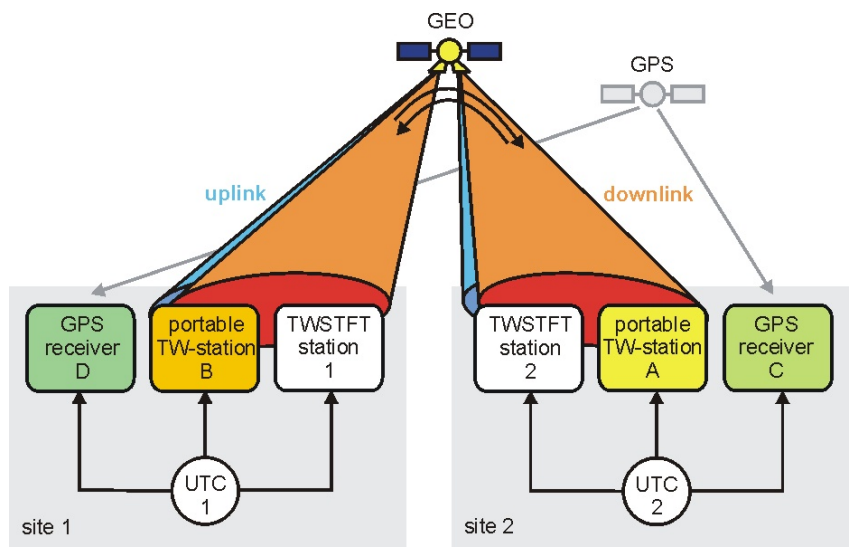

Figure 4. The calibration equipment after exchanging the portable TWSTFT stations and the GPS receivers.

\section{Distillation of Delays}

With the equations (4) to (8) we have the tools to extract the single delay components we need for a calibration of the ground stations and the transponder delays. Note that the measurements in equations (4), (5), and (6) as well as in (4), (7), and (8) should be recorded simultaneously. In this case we are allowed to drop the time scale differences in these two groups. We concentrate on the TWSTFT equipment first, combining (4) with (5) and (7):

$$
\begin{aligned}
1 / 2 & {[\mathrm{TW}(1)-\mathrm{TW}(2)]_{\mathrm{A} 1, \mathrm{~B} 2}+1 / 2[\operatorname{DLD}(1)-\mathrm{DLD}(2)] } \\
& =1 / 2\left[\mathrm{TW}\left(\mathrm{A}_{1}\right)-\mathrm{TW}\left(\mathrm{B}_{2}\right)\right]+1 / 2[\mathrm{DLD}(\mathrm{A})-\operatorname{DLD}(\mathrm{B})]
\end{aligned}
$$

$$
\begin{aligned}
& 1 / 2 {[\mathrm{TW}(1)-\mathrm{TW}(2)]_{\mathrm{B} 1, \mathrm{~A} 2}+1 / 2[\mathrm{DLD}(1)-\mathrm{DLD}(2)] } \\
&=1 / 2\left[\mathrm{TW}\left(\mathrm{B}_{1}\right)-\mathrm{TW}\left(\mathrm{A}_{2}\right)\right]+1 / 2[\mathrm{DLD}(\mathrm{B})-\mathrm{DLD}(\mathrm{A})]
\end{aligned}
$$

In (9) the index "A1,B2" denotes that the measurment is taken when station $\mathrm{A}$ is at site 1 and station $\mathrm{B}$ is at site 2 . The combinations $(9)+(10)$ and $(9)-10)$ give, respectively:

$$
\begin{aligned}
1 / 2 & {[\mathrm{TW}(1)-\mathrm{TW}(2)]_{\mathrm{A} 1, \mathrm{~B} 2}+1 / 2[\mathrm{TW}(1)-\mathrm{TW}(2)]_{\mathrm{B} 1, \mathrm{~A} 2} } \\
& +[\mathrm{DLD}(1)-\mathrm{DLD}(2)] \\
& =1 / 2\left[\mathrm{TW}\left(\mathrm{A}_{1}\right)-\mathrm{TW}\left(\mathrm{B}_{2}\right)\right]+1 / 2\left[\mathrm{TW}\left(\mathrm{B}_{1}\right)-\mathrm{TW}\left(\mathrm{A}_{2}\right)\right] \\
1 / 2 & {[\mathrm{TW}(1)-\mathrm{TW}(2)]_{\mathrm{A} 1, \mathrm{~B} 2}-1 / 2[\mathrm{TW}(1)-\mathrm{TW}(2)]_{\mathrm{B} 1, \mathrm{~A} 2} } \\
& =1 / 2\left[\mathrm{TW}\left(\mathrm{A}_{1}\right)-\mathrm{TW}\left(\mathrm{B}_{2}\right)\right]-1 / 2\left[\mathrm{TW}\left(\mathrm{B}_{1}\right)-\mathrm{TW}\left(\mathrm{A}_{2}\right)\right] \\
& +[\mathrm{DLD}(\mathrm{A})-\mathrm{DLD}(\mathrm{B})]
\end{aligned}
$$

For clarity we sort both equations:

$$
\begin{aligned}
& {[\operatorname{DLD}(1)-\mathrm{DLD}(2)]} \\
& =\left\{1 / 2\left[\mathrm{TW}\left(\mathrm{A}_{1}\right)-\mathrm{TW}\left(\mathrm{B}_{2}\right)\right]-1 / 2[\mathrm{TW}(1)-\mathrm{TW}(2)]_{\mathrm{A} 1, \mathrm{~B} 2}\right\}_{\mathrm{I}} \\
& +\left\{1 / 2\left[\mathrm{TW}\left(\mathrm{B}_{1}\right)-\mathrm{TW}\left(\mathrm{A}_{2}\right)\right]-1 / 2[\mathrm{TW}(1)-\mathrm{TW}(2)]_{\mathrm{B} 1, \mathrm{~A} 2}\right\}_{\mathrm{II}}
\end{aligned}
$$

$$
\begin{aligned}
& {[\mathrm{DLD}(\mathrm{A})-\mathrm{DLD}(\mathrm{B})]} \\
& =\left\{1 / 2[\mathrm{TW}(1)-\mathrm{TW}(2)]_{\mathrm{A} 1, \mathrm{~B} 2}-1 / 2\left[\mathrm{TW}\left(\mathrm{A}_{1}\right)-\mathrm{TW}\left(\mathrm{B}_{2}\right)\right]\right\}_{\mathrm{I}} \\
& -\left\{1 / 2[\mathrm{TW}(1)-\mathrm{TW}(2)]_{\mathrm{B} 1, \mathrm{~A} 2}-1 / 2\left[\mathrm{TW}\left(\mathrm{B}_{1}\right)-\mathrm{TW}\left(\mathrm{A}_{2}\right)\right]\right\}_{\mathrm{II}}
\end{aligned}
$$

The terms in the first curly brackets in (13) and (14) represent the measurements when the portable stations $\mathrm{A}$ and $\mathrm{B}$ are located at the sites 1 and 2, respectively (index I). The terms in the second curly brackets represent the measurements with exchanged portable stations (index II). From (13) we get the double delay difference between the operational stations $[\mathrm{DLD}(1)-\mathrm{DLD}(2)]$ and from (14) we get the double delay difference between the portable stations $[\operatorname{DLD}(\mathrm{A})-\mathrm{DLD}(\mathrm{B})]$.

To get access to the transponder delay difference we need the help of the GPS receivers, here combining (5) with (6) and (7) with (8):

$$
\begin{aligned}
& \operatorname{GPS}\left(\mathrm{C}_{1}\right)-\mathrm{GPS}\left(\mathrm{D}_{2}\right)+\mathrm{CD} \\
& \quad=1 / 2\left[\mathrm{TW}\left(\mathrm{A}_{1}\right)-\mathrm{TW}\left(\mathrm{B}_{2}\right)\right]+1 / 2[\mathrm{DLD}(\mathrm{A})-\mathrm{DLD}(\mathrm{B})] \\
& \quad+1 / 2[\mathrm{SP}(2)-\mathrm{SP}(1)]+[\mathrm{SCD}(2)-\mathrm{SCD}(1)] \\
& \mathrm{GPS}\left(\mathrm{D}_{1}\right)-\mathrm{GPS}\left(\mathrm{C}_{2}\right)-\mathrm{CD} \\
& \quad=1 / 2\left[\mathrm{TW}\left(\mathrm{B}_{1}\right)-\mathrm{TW}\left(\mathrm{A}_{2}\right)\right]+1 / 2[\mathrm{DLD}(\mathrm{B})-\mathrm{DLD}(\mathrm{A})] \\
& \quad+1 / 2[\mathrm{SP}(2)-\mathrm{SP}(1)]+[\mathrm{SCD}(2)-\mathrm{SCD}(1)]
\end{aligned}
$$


The combinations $(15)+(16)$ and (15) - (16) give:

$$
\begin{aligned}
& {\left[\operatorname{GPS}\left(\mathrm{C}_{1}\right)-\operatorname{GPS}\left(\mathrm{D}_{2}\right)\right]+\left[\mathrm{GPS}\left(\mathrm{D}_{1}\right)-\operatorname{GPS}\left(\mathrm{C}_{2}\right)\right]} \\
& \quad=1 / 2\left[\mathrm{TW}\left(\mathrm{A}_{1}\right)-\mathrm{TW}\left(\mathrm{B}_{2}\right)\right]+1 / 2\left[\mathrm{TW}\left(\mathrm{B}_{1}\right)-\mathrm{TW}\left(\mathrm{A}_{2}\right)\right] \\
& \quad+[\mathrm{SP}(2)-\mathrm{SP}(1)]+2[\mathrm{SCD}(2)-\mathrm{SCD}(1)]
\end{aligned}
$$$$
\left[\operatorname{GPS}\left(\mathrm{C}_{1}\right)-\operatorname{GPS}\left(\mathrm{D}_{2}\right)\right]-\left[\operatorname{GPS}\left(\mathrm{D}_{1}\right)-\operatorname{GPS}\left(\mathrm{C}_{2}\right)\right]
$$$$
=1 / 2\left[\mathrm{TW}\left(\mathrm{A}_{1}\right)-\mathrm{TW}\left(\mathrm{B}_{2}\right)\right]-1 / 2\left[\mathrm{TW}\left(\mathrm{B}_{1}\right)-\mathrm{TW}\left(\mathrm{A}_{2}\right)\right]
$$$$
+[\operatorname{DLD}(\mathrm{A})-\mathrm{DLD}(\mathrm{B})]-2 \mathrm{CD}
$$

Again, for clarity we sort (18) in a different way:

$$
\begin{aligned}
& {[\mathrm{SP}(2)-\mathrm{SP}(1)]} \\
& =\left\{\left[\operatorname{GPS}\left(\mathrm{C}_{1}\right)-\operatorname{GPS}\left(\mathrm{D}_{2}\right)\right]-1 / 2\left[\mathrm{TW}\left(\mathrm{A}_{1}\right)-\mathrm{TW}\left(\mathrm{B}_{2}\right)\right]\right\}_{\mathrm{I}} \\
& +\left\{\left[\operatorname{GPS}\left(\mathrm{D}_{1}\right)-\operatorname{GPS}\left(\mathrm{C}_{2}\right)\right]-1 / 2\left[\mathrm{TW}\left(\mathrm{B}_{1}\right)-\mathrm{TW}\left(\mathrm{A}_{2}\right)\right]\right\}_{\mathrm{II}} \\
& +2[\mathrm{SCD}(2)-\operatorname{SCD}(1)]
\end{aligned}
$$

Using eq. (19) we can determine the transponder delay difference $[\mathrm{SP}(2)-\mathrm{SP}(1)]$ on the launched satellite! From eq.

\begin{tabular}{|c|c|c|c|c|}
\hline Class & $\begin{array}{c}\text { Reported } \\
\text { uncertainty } \\
\text { (ns) }\end{array}$ & Reference & Comments & $\begin{array}{l}\text { Estimation for } \\
\text { this work } \\
\text { (ns) }\end{array}$ \\
\hline \multirow{2}{*}{$u_{\mathrm{A}, 1}$} & $0.17-\mathbf{0 . 4 3}$ & [5], [6] & $\begin{array}{l}\text { Ku-band-X-band TWSTFT during calibration trip } \\
\text { Estimated from the standard deviation of the differences between two TWSTFT links in } \\
\text { parallel. The data are 2-min-averages (10-min) of } 1 \text {-sec-data processed according to certain } \\
\text { rules. }\end{array}$ & \multirow{2}{*}{0.5} \\
\hline & 0.53 & [1] & $\begin{array}{l}6 \text { months of Ku-band }-X \text {-band TWSTFT } \\
\text { Standard deviation of double differences of data taken every two hours. Each data point is } \\
\text { the average of } 2 \mathrm{~min}(10 \mathrm{~min}) \text { of } 1 \text {-sec-data processed according to certain rules. }\end{array}$ & \\
\hline \multirow{3}{*}{$u_{\mathrm{A}, 2}$} & 0.49 & this work & $\begin{array}{l}\text { UTC }(\text { NICT) - UTC (PTB) via TWSTFT and GPS PPP } \\
\text { Standard deviation of double differences computed from GPS PPP solutions (available } \\
\text { every } 5 \mathrm{~min} \text { ) and of hourly TWFTFT data (average of } 5 \mathrm{~min} 1 \text {-sec-data). }\end{array}$ & \multirow{3}{*}{0.5} \\
\hline & 0.53 & [1] & $\begin{array}{l}\text { UTC(NIST) - UTC(PTB) via TWSTFT and GPS C/A } \\
\text { Standard deviation of } 3 \text { months of double differences between TWSTFT (12 data points } \\
\text { per day) and GPS (standard CGGTTS schedule). }\end{array}$ & \\
\hline & 0.71 & [1] & $\begin{array}{l}\text { UTC(NIST) - UTC(PTB) via TWSTFT and GPS C/A single frequency receivers } \\
\text { Same computation but using a } 6 \text { months data set. }\end{array}$ & \\
\hline \multirow{3}{*}{$u_{\mathrm{B}, 1}$} & 0.05 & [7] & $\begin{array}{l}\text { Asian TWSTFT calibration campaign } \\
\text { Difference between the averaged common clock differences between a portable and a } \\
\text { reference station before and after the calibration trip. }\end{array}$ & \multirow{3}{*}{0.9} \\
\hline & $0.09-\mathbf{0 . 8 4}$ & [8] & $\begin{array}{l}\text { USNO TWSTFT campaigns } \\
\text { Differenece between the common clock differences between a portable and a reference } \\
\text { station before and after the calibration trip. }\end{array}$ & \\
\hline & $0.20-0.70$ & [1] & $\begin{array}{l}\text { European campaigns } \\
\text { Uncertainty derived from measurements of common clock differences between a portable } \\
\text { and a reference station before and after the calibration trip. }\end{array}$ & \\
\hline \multirow{4}{*}{$u_{\mathrm{B}, 2}$} & 0.28 & [3] & $\begin{array}{l}\text { GPS receiver calibration, } 25 d+\text { travelling, } P P P \\
\text { Difference between the averaged common clock differences before and after the calibration } \\
\text { trip. }\end{array}$ & \multirow{4}{*}{1.5} \\
\hline & 0.7 & [9] & $\begin{array}{l}\text { GPS receiver calibration, } 44 d+\text { travelling,, } P 1 \text { code } \\
\text { Difference between the averaged common clock differences before and after the calibration } \\
\text { trip. }\end{array}$ & \\
\hline & 1.3 & [9] & $\begin{array}{l}\text { GPS receiver calibration, } 44 d+\text { travelling, } P 2 \text { code } \\
\text { Difference between the averaged common clock differences before and after the calibration } \\
\text { trip. }\end{array}$ & \\
\hline & 1.48 & this work & $\begin{array}{l}\text { GPS receiver link operation, } P P P \\
\text { Preliminarily taken as uncertainty for receiver exchange on long baselines due to the } \\
\text { observation of a phase jump time transfer data between NICT and PTB after a forced restart } \\
\text { of the two receivers which is not understood at present. }\end{array}$ & \\
\hline$u_{\mathrm{B}, 3}$ & 0.5 & [1] & TIC specifications & 0.5 \\
\hline
\end{tabular}
(16) we can extract [DLD(A) - DLD(B)] - 2 CD:

$$
\begin{aligned}
& {[\operatorname{DLD}(\mathrm{A})-\operatorname{DLD}(\mathrm{B})]-2 \mathrm{CD}} \\
& =\left\{\left[\operatorname{GPS}\left(\mathrm{C}_{1}\right)-\operatorname{GPS}\left(\mathrm{D}_{2}\right)\right]-1 / 2\left[\mathrm{TW}\left(\mathrm{A}_{1}\right)-\mathrm{TW}\left(\mathrm{B}_{2}\right)\right]\right\}_{\mathrm{I}} \\
& -\left\{\left[\operatorname{GPS}\left(\mathrm{D}_{1}\right)-\operatorname{GPS}\left(\mathrm{C}_{2}\right)\right]-1 / 2\left[\mathrm{TW}\left(\mathrm{B}_{1}\right)-\mathrm{TW}\left(\mathrm{A}_{2}\right)\right]\right\}_{\text {II }}
\end{aligned}
$$

TABLE I. ESTIMATE OF CONTRIBUTIONS TO THE OVERALL UNCERTAINTY BUDGET: COMPARISON OF TWO TWSTFT LINKS: $U_{\mathrm{A}, 1}$; COMPARISON OF A TWSTFT WITH A GPS LINK: $U_{\mathrm{A}, 2}$; STABILITY OF A TWSTFT STATION DURING THE TRIP: $U_{\mathrm{B}, 1}$; STABILITY OF THE GPS RECEIVERS AFTER EXCHANGE: $U_{\mathrm{B}, 2}$; OTHER SYSTEMATICS, E.G. THE CONNECTION TO THE LOCAL UTC REALIZATION: $U_{\mathrm{B}, 3}$. 
Combining (18) with (14) the differential delay CD between the two GPS receivers can be determined without the need for collocation of the two devices or for a third travelling receiver. Furthermore, the terms of the portable TW-stations vanish.

\section{UNCERTAINTY CONTRIBUTIONS}

Each delay is determined with a certain combination of measurements and relies on the stability of the involved equipment during the campaign. For an uncertainty estimation we use data already published in the literature, and some own experimental results. These have been compiled in Table 1 together with a brief describtion of the data basis for the estimateion of the uncertainty. Detailed information can be found in the listed references.

We state $u_{\mathrm{A}, 1}$ as the statistical uncertainty the of the difference of two TWSTFT links operated in parallel. As shown in Table 1 (in bold numbers), we consider the maximum standard deviation of such two links in parallel during previous calibration experiments between the USNO and PTB as the reference. However, a long term comparison over 6 months revealed a slightly higher value.

Secondly, $u_{\mathrm{A}, 2}$ is the statistical uncertainty of the comparison of one TWSTFT link and one GPS link operated in parallel. Older comparisons between NIST and PTB using the GPS C/A code gives standard deviations between $0.53 \mathrm{~ns}$ and $0.71 \mathrm{~ns}$. A recent result comparing the time scales between NICT and PTB using TWSTFT and the GPS PPP evaluation technique yielded a slightly better value of $0.5 \mathrm{~ns}$ (see Fig. 5), which we consider as an achievable value.

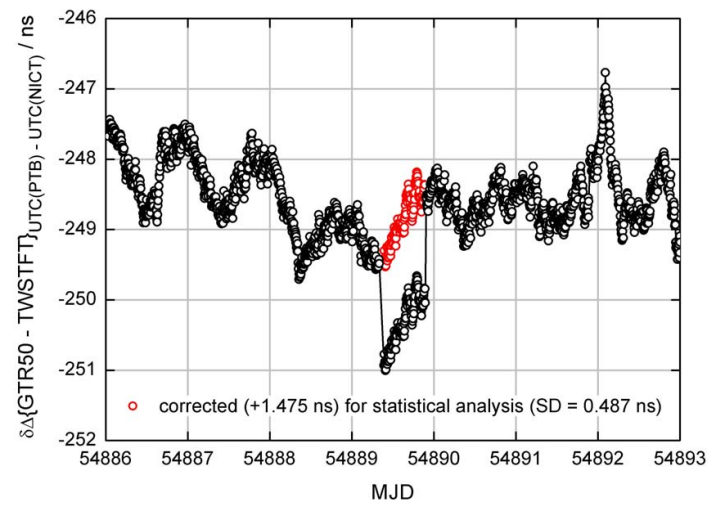

Figure 5. Double Difference GPS PPP - TWSTFT of the link UTC(NICT) - UTC(PTB) during 1 week of observation (MJD 54886 corresponds to 24 Feb 2009) as an example for the typical duration of a calibration period. On MJD 54889 both GPS receivers were switched off at 9 UTC and switched on after approximately one hour. The PTB receiver was disconnected a second time before midnight of the same day. Coincidentily with this, two jumps occurred in the GPS PPP time tansfer data evaluation. The red data points have been corrected for these jumps. The standard deviation (SD) is evaluated from the entire corrected data set.

The assumption that the internal signal delay of the travelling reference equipment does not change is the most crucial point during the calibration campaign. It can be tested by operating the portable equipment side-by-side to a stationary counterpart before and right after the campaign (see [1] for details how the uncertainties are usually determined). $u_{\mathrm{B}, 1}$ and $u_{\mathrm{B}, 2}$ are the accompanying uncertainty contributions for the portable TWSTFT groundstations and the GPS receivers, respectively.

Finally we state $u_{\mathrm{B}, 3}=0.5 \mathrm{~ns}$ for the uncertainty of the local connections to the reference clock by means of a time interval counter (TIC), based on the specifications of a typically used TIC.

\section{UNCERTAINTY BUDGETS}

The combined uncertainty estimations of the delay differences of the different parts of the link are computed using the single uncertainty contributions $u_{i}$ of Table 1 following:

$$
U=\sqrt{\sum_{i} u_{i}^{2}}
$$

The results are summarized in Table 2. With the introduced technique it is possible to calibrate the differential delay between the fixed Earth stations as well as the portable ground stations at the uncertainty level of $1.3 \mathrm{~ns}$. The transponder delay on the launched satellite can be determined with an uncertainty of 2 ns.

TABLE II. ESTIMATED UNCERTAINTIES OF THE DETEREMINATION OF THE THE DELAY DIFFERENCES OF THE USED TWSTFT EQUIPMENT (THE FIXED EARTH STATIONS: DLD $(1)$ - DLD(2), THE PORTABLE STATIONS: DLD(A) - DLD(B), SATELLITE TRANSPONDER SP(2) - SP(1), GPS RECEIVERS (CD), AND THE TWSTFT LINK AS A WHOLE (TWSTFT-LINK BY GPS).

\begin{tabular}{|l|l|l|}
\hline \multicolumn{1}{|c|}{$\boldsymbol{U}[\mathrm{Delay}$ difference] } & Contributions $\boldsymbol{u}_{\mathbf{i}}$ & $\begin{array}{c}\text { Uncertainty } \\
\text { estimation } \\
\text { (ns) }\end{array}$ \\
\hline$U[\mathrm{DLD}(1)-\mathrm{DLD}(2)]$ & $2 u_{\mathrm{A}, 1}, u_{\mathrm{B}, 1}, u_{\mathrm{B}, 3}$ & 1.3 \\
\hline$U[\mathrm{DLD}(\mathrm{A})-\mathrm{DLD}(\mathrm{B})]$ & $2 u_{\mathrm{A}, 1}, u_{\mathrm{B}, 1}, u_{\mathrm{B}, 3}$ & 1.3 \\
\hline$U[\mathrm{SP}(2)-\mathrm{SP}(1)]$ & $2 u_{\mathrm{A}, 2}, u_{\mathrm{B}, 1}, u_{\mathrm{B}, 2}, u_{\mathrm{B}, 3}$ & 2.0 \\
\hline$U[\mathrm{CD}]$ & $2 u_{\mathrm{A}, 2}, u_{\mathrm{B}, 2}, u_{\mathrm{B}, 3}$ & 1.8 \\
\hline $\begin{array}{l}U[\mathrm{TWSTFT}-\text { link by } \\
\mathrm{GPS}]\end{array}$ & $u_{\mathrm{A}, 2}, U[\mathrm{CD}]$ & 1.9 \\
\hline
\end{tabular}

Remarkable is the possibility to calibrate the TWSTFT link as a whole by means of exchanged GPS receivers. This can be done in two steps: First the differential delay CD between the GPS receivers is determined and in a second step the difference between the TWSTFT and the GPS link is determined. The overall uncertainty is below $2 \mathrm{~ns}$ in this case. This low uncertainty for a GPS calibration of a TWSTFT link is achieved by taking into account that during the short duration of a calibration campaign the GPS equipment delay is significantly more stable than observed during long term operation (see [3] for a detailed discussion).

Finally we want to address briefly some important points which we plan to address in future work:

1. In this report we do not consider for the delay variation of the portable TWSTFT stations if transmit and receive frequencies have to be adjusted during the exercise. This is an 
crucial point for determing $\operatorname{DLD}(1)-\mathrm{DLD}(2)$, DLD(A) $\operatorname{DLD}(\mathrm{B})$, and $\mathrm{SP}(2)-\mathrm{SP}(1)$, and it might lead to an increase of the uncertainty. Nevertheless, the possibility to calibrate a TWSTFT as a whole is not affected by this. Commonly, it is mandatory to keep all operational parameters unchanged during a calibration campaign.

2. Beside transponder configurations as described in this report, there is at least one special transponder configuration case on the telecommunication satellite IS-4. On this satellite one wide area uplink antenna covers Asia and Europe and is connected to two local downlink spot beams for Asia and Europe, respectively. This might give some advantages to the overall calibration procedure and uncertainty.

3. The possibility to calibrate a TWSTFT link as a whole by means of GPS with an uncertainty on the level of 2 ns or below offers a rather cheap and straightforward alternative to the rather sophisticated calibration campaigns using a portable TWSTFT station. Promising results have been already discussed [3] and the procedure should be verified by repetition.

\section{CONCLUSION}

In this report we have discussed an experimental procedure which could allow determination of all important delay differences in a long baseline link including the differential delays between the operational ground stations as well as the differential transponder delay between the two separated transponders used on the satellite in use. Our scheme consists of two portable TWSTFT stations and two GPS receivers which are exchanged between the two ground stations to be calibrated. We make use of the fact that the statistical uncertainty of GPS time transfer is actually significantly smaller during the short period of the envisaged campaign (about $1 \mathrm{~ns}$ ) compared with the widely discussed 5-ns estimate: The latter should take into account long-term delay variations which have been observed in the past. We thus estimate that the overall uncertainty for the calibrations do not exceed the level of 2 ns.

\section{REFERENCES}

[1] D. Piester, A. Bauch, L. Breakiron, D. Matsakis, B. Blanzano, O. Koudelka: Time transfer with nanosecond accuracy for the realization of International Atomic Time; Metrologia, vol. 45, no. 2, pp. 185-198, 2008.

[2] Z. Jiang, G. Petit: Combination of TWSTFT and GNSS for accurate UTC time transfer; Metrologia, vol. 46, pp. 305-314, 2009.

[3] H. Esteban, T. Feldmann, J. Palacio, A. Bauch, F. J. Galindo, D. Piester: A GPS Calibration Trip Experience Between ROA and PTB; Proc. European Frequency and Time Forum \& IEEE International Frequency Control Symposium EFTF - IFCS 2009 Joint Conference, 20-24 Apr 2009, Besançon, France.

[4] ITU Radiocommunication Sector: The operational use of two-way satellite time and frequency transfer employing PN codes; Recommendation ITU-R TF.1153-2, Geneva, Switzerland, 2003.

[5] D. Piester, A. Bauch, J. Becker, T. Polewka, A. McKinley, L. Breakiron, A. Smith, B. Fonville, D. Matsakis: Two-Way Satellite Time Transfer between USNO and PTB; Proc. 2005 Joint IEEE International Frequency Control Symposium and Precise Time and Time Interval Systems and Applications Meeting, 29-31 Aug 2005, Vancouver, BC, Canada, pp. 316-323, 2005.

[6] D. Piester, A. Bauch, J. Becker, T. Polewka, M. Rost, D. Sibold, E. Staliuniene: PTB's Time and Frequency Activities in 2006: New DCF77 Electronics, New NTP Servers, and Calibration Activities; Proc. $38^{\text {th }}$ Annual Precise Time and Time Interval (PTTI) Systems and Applications Meeting, 5-7 Dec 2006, Reston, Virginia, USA, pp. 37-47, 2007.

[7] M. Fujieda, M. Aida, H. Maeno, L. Q. Tung, R. Tabuchi: Calibration of Two-way time transfer between NICT and TL; Technical Report, NICT, Tokyo, Japan, 2006.

[8] L. Breakiron, A. Smith, B. Fonville, E. Powers, D. Matsakis: The accuracy of two-way satellite time transfer calibrations, Proc. 36th Annual Precise Time and Time Interval (PTTI) Meeting, 7-9 Dec 2004, Washington, DC, USA, pp. 139-148, 2005.

[9] P. Uhrich, D. Valat, P. Prioa, G. Cibiel, L. Yaigre: GPS receiver relative and absolute calibration campaigns for the Galileo Time Service Provider; Program of the European Frequency and Time Forum \& International Frequency Control Symposium EFTF - IFCS 2009 Joint Conference, Besançon, France, 20-24 Apr 2009. See also: P. Uhrich, D. Valat, 2009 GPS Common-View Receiver Relative Calibration Campaign Report; Fidelity WP 3270 Report, LNESYRTE, Paris, France, 2009. 